\title{
Tecnologia digital e a BNCC no contexto de Língua Inglesa para crianças: novas possibilidades e desafios
}

\author{
Adriana Jesuíno Francisco ${ }^{\mathrm{i}}$ \\ Ana Luzia Videira Parisotto ${ }^{\text {ii }}$
}

\section{RESUMO}

Este artigo tem por objetivo apresentar a proposição de um Plano Anual de Ensino com temas e atividades baseadas nas competências estabelecidas na BNCC (Base Nacional Comum Curricular) e com foco no desenvolvimento de letramento digital para crianças da segunda etapa do Ensino Infantil, no contexto de Língua Inglesa. Por meio de revisão de literatura, busca-se refletir e trazer contribuições sobre a prática docente atrelada à tecnologia digital, aos multiletramentos, à formação continuada de professores, e à importância de reconhecer o Inglês como língua franca, sob a perspectiva comunicativa. Os resultados desta pesquisa de base qualitativa apontam que nem sempre uma infraestrutura tecnológica adequada garante a exploração dos recursos digitais, já que são necessários processos formativos que possibilitem a reflexão sobre o ensino de Língua Inglesa na educação infantil.

Palavras-chave: Tecnologia digital; Ensino de Língua Inglesa; Educação Infantil; BNCC.

\begin{abstract}
This article presents a proposal for an annual teaching plan with themes and activities based on the competencies established in the BNCC (National Common Curricular Base) and aimed at developing digital literacy in K2-level (second year of kindergarten) children in the context of English Language Teaching (ELT). By means of a literature review, we seek to contribute to teaching practices associated with digital technologies, multi-literacies, and continuing teacher education and reflect on the importance of acknowledging English as a lingua franca from a communicative point of view. The results in this qualitative research suggest that adequate technological infrastructure does not suffice to ensure full utilization of digital resources since teacher education
\end{abstract}

\footnotetext{
${ }^{\text {i }}$ Mestranda em Educação (Unesp/Presidente Prudente). Licenciatura em Letras e Pedagogia. Vinculada ao Grupo de Pesquisa e Avaliação Centro de Políticas Educacionais (GAPE), e Centro de Estudos em Leitura e Literatura Infantil e Juvenil (CELLIJ). ORCID: http://orcid.org/0000-0002-7589-6556 E-mail: adriana.francisco@unesp.br

ii Mestrado e doutorado em Letras. Docente e pesquisadora em RDIDP na Faculdade de Ciências e Tecnologia/Unesp, câmpus de Presidente Prudente. Atua no Departamento de Educação e no Programa de Pós-Graduação em Educação. Líder do Grupo de Pesquisa "Formação de Professores e Práticas de Ensino na Educação Básica e Superior”. https://orcid.org/0000-0001-9786-745X / ana-luzia.parisotto@unesp.br
} 
programs need to embrace more opportunities for reflection on ELT in early childhood education.

Keywords: Digital Technology; English Language Teaching; Early Childhood Education; BNCC.

\section{INTRODUÇÃO}

Este artigo aborda o ensino de Língua Inglesa para crianças, enfatizando o uso das tecnologias digitais pelo viés da Base Nacional Comum Curricular (BNCC). A motivação para realização deste trabalho surgiu da necessidade de se refletir, discutir e tecer contribuições acerca da prática docente em Língua Inglesa (LI) com relação ao uso das novas tecnologias em sala de aula. A inquietação central foi a tentativa de buscar respostas sobre como trabalhar, efetivamente, o letramento digital com crianças na faixa etária de cinco anos, cursando a segunda etapa do Ensino Infantil, de uma escola pública municipal, do interior de São Paulo.

Observamos que, praticamente, todos os docentes que lecionam LI para crianças na rede municipal de ensino têm como formação inicial o curso de Letras, cujo currículo não aborda nenhuma disciplina relacionada ao ensino de línguas estrangeiras ou de língua materna para crianças. Verificamos também, a partir de conversas informais e em cursos de formação, que a maioria sentiu a necessidade de compreender melhor o processo de ensino e aprendizagem de crianças que cursam o Ensino Fundamental I, a fim de atrelar esse conhecimento ao ensino de LI. Para tanto, tais docentes buscaram uma segunda licenciatura em Pedagogia, visando a aprimorar o desempenho e as habilidades em sala de aula ao considerar as etapas de desenvolvimento da criança. $\mathrm{O}$ fato é que o curso de Letras não forma estudantes para trabalhar com crianças, e o curso de Pedagogia não prepara para o ensino de Língua Inglesa.

Uma das autoras do presente artigo, com formação em Letras e em Pedagogia, que já lecionava anteriormente LI para crianças do primeiro ao quinto ano, teve sua primeira experiência com Educação Infantil e, neste percurso, encontrou dois grandes desafios. O primeiro deu-se pelo fato de o município de Assis/SP, até aquele momento, 
não ter Plano de Ensino. Isso significa que os professores não tinham um parâmetro a seguir, pois ainda não havia uma legislação específica voltada ao componente curricular na grade da Educação Infantil.

O segundo desafio foi decorrente da inserção da Base Nacional Comum Curricular (BNCC), que propiciou um novo direcionamento para a elaboração dos Planos de Ensino, todavia com poucas oportunidades de formação e discussão sobre as potencialidades e fragilidades desse documento para reflexão sobre o ensino de LI. Na BNCC, está previsto o uso das tecnologias, objetivando que os alunos as utilizem de forma crítica e responsável ao longo da Educação Básica. Porém, a questão da formação de professores para o uso adequado das tecnologias tem sido muito discutida e problematizada por vários autores (LEFFA, 2005; MENEZES, 2013; CELANI, 2002; GIMENEZ, 2002; ROCHA, 2012).

Pesquisadores enfatizam a importância de maior investimento no letramento digital e na formação de professores. Vilson José Leffa (2005) e Roxane Rojo (2013), por exemplo, apontam ainda que a maior dificuldade para o uso das tecnologias na Educação no Brasil está relacionada à formação de professores, principalmente, por falta de formação continuada.

O contexto de ensino no qual uma das pesquisadoras atua é privilegiado se comparado à maioria dos contextos brasileiros, pois a rede municipal de ensino de Assis/SP oferece infraestrutura digital (computador, lousa digital e internet) em aproximadamente oitenta por cento das salas de aula. Assim, tal cenário possibilita a inserção, nas aulas de LI, de atividades multimodais. O que nos falta é uma formação continuada e encontros com demais professores da rede de ensino com o objetivo de trocar experiências e de estudar propostas de desenvolvimento de letramento digital. Nesse sentido, este trabalho é uma tentativa de aproximação para discussão dessa problemática.

Desse modo, temos como objetivo, neste artigo, apresentar a proposição de um planejamento - com temas para atividades - com base nas competências da BNCC (BRASIL, 2017) e com foco no desenvolvimento de letramento digital para crianças da segunda etapa do Ensino Infantil.

Assim, este artigo está organizado do seguinte modo: primeiro, apresentaremos o referencial teórico no qual nosso trabalho está embasado; em seguida, o percurso 
metodológico, para, por fim, apresentarmos o Plano de Ensino e uma proposta de inserção de letramento digital com base nos projetos da escola.

\section{FUNDAMENTAÇÃO TEÓRICA}

\section{Ensino de Inglês na Educação Infantil}

O Guia Curricular para a Língua Inglesa (2013) traz diversas sugestões que colaboram para que professores de LI desenvolvam suas atividades em contextos significativos, ressaltando que o aprendizado de uma língua estrangeira na educação básica proporciona aos alunos uma nova concepção da natureza da linguagem, compreendendo seu funcionamento, além de intensificar o entendimento da língua materna e a compreensão de como a língua funciona.

Destaca ainda que, no cenário de LI para crianças, é preciso respeitar as especificidades do seu processo de aprendizagem, oferecendo um ambiente lúdico e um ensino gradativo. Na mesma medida, a pretensão sobre a produção das crianças também deve ser gradual, tendo em vista que o uso da LI pelos pequenos aprendizes deve corresponder às práticas discursivas da sua realidade.

Os Parâmetros Curriculares Nacionais de Língua Estrangeira (PCNs), referindose ao estudante, ressaltam que, "ao entender o outro e sua alteridade, pela aprendizagem de uma língua estrangeira, ele aprende mais sobre si mesmo e sobre o mundo plural marcado por valores culturais diferentes e maneiras diversas de organização política e social” (BRASIL, 1998, p. 19).

Logo, com o propósito de atribuir sentido ao ensino, de maneira a vivenciar a prática tanto em sala de aula quanto em ambientes externos a ela, a BNCC (BRASIL, 2017) reestruturou as áreas de conhecimento tradicional e trouxe cinco campos de experiências essenciais para o desenvolvimento infantil. Vale destacar ainda, com relação aos PCNs de Língua Inglesa, a proposta do campo de experiência “ $\mathrm{O}$ eu, o outro e nós". Este campo está relacionado ao autoconhecimento e à construção de relações, pois, a partir do momento em que a criança conseguir entender melhor a si mesma, ela se tornará um indivíduo apto a aceitar as diferenças nas relações e as diversidades culturais, além de facilitar a compreensão do mundo ao seu redor. De maneira lúdica, os conceitos relacionados ao campo "o eu, o outro e nós" - consciência cidadã, 
autoconhecimento, coletividade, respeito, responsabilidade - podem ser incutidos de maneira natural. $\mathrm{O}$ ensino e aprendizagem da LI nos anos iniciais devem priorizar a abordagem comunicativa.

José Carlos Paes de Almeida Filho (2008) destaca a importância desse tipo de abordagem para o ensino e aprendizagem de LI nos anos iniciais, visto que valoriza aspectos relacionados à oralidade e enfatiza a produção de significados no uso da língua alvo, o que é condizente com a etapa de ensino estudada, em que não se devem priorizar atividades metalinguísticas. Dessa forma, devemos fazer uso, além da motivação da própria criança, de jogos, brincadeiras, contação de histórias e atividades em duplas e grupos, que sejam significativas para a infância e que realmente façam sentido para a formação intelectual e social. Ressaltamos que as novas tecnologias e os recursos multimodais - gama de combinações entre linguagem verbal e não verbal, como palavras, gestos, imagens em movimento, sons, etc. -, quando utilizados de forma adequada, podem ser grandes aliados para o ensino e aprendizagem. Apresentaremos a seguir três pesquisas que apontam a importância dos recursos tecnológicos no contexto escolar, especificamente na Educação Infantil.

Andréia Regina Pereira e Roseli de Deus Lopes (2005) destacam a importância da tecnologia na Educação Infantil, visto que, com

[...] o uso de ferramentas tecnológicas educacionais desde cedo ampliaremos a possibilidade de formar indivíduos mais criativos que estarão adquirindo novos conhecimentos e integrando-se com um novo modo de aprender e de interagir com a sociedade (PEREIRA; LOPES, 2005, p. 24).

A partir de pesquisas e visitas realizadas em escolas de Educação Infantil, as autoras criaram o Ambiente Legal, o qual permite que a criança se expresse, em seu contexto social, de maneira criativa ao contar histórias, possibilitando, assim, o uso da linguagem oral e a ampliação de vocabulário.

Andréia Regina Pereira e Ana Paula Peruzza (2002) criaram um software educativo para o contexto escolar denominado Realidade Virtual. Para as autoras, "esta ferramenta didática irá trabalhar conceitos de cores, formas, números, letras, etc, de forma natural, para crianças em fase pré-escolar, em um ambiente virtual que representa o ambiente real no qual a criança está acostumada" (2002, p. 388). 
Gilvana Costa Barbosa (2014), em Tecnologias digitais: Possibilidades e desafios na Educação Infantil, artigo que é resultado de pesquisas bibliográfica e documental, busca discutir como a escola utiliza as tecnologias digitais e quais as contribuições pedagógicas para o contexto educacional da Educação Infantil. Salienta que o trabalho pedagógico com as TICs, na Educação Infantil, possibilita uma aprendizagem autônoma, tornando-a mais significativa de maneira a ampliar as habilidades do pensar.

Portanto, ensinar LI para crianças significa focar na formação identitária e no agir do aluno por meio do contexto de utilização da língua como prática social (CRISTOVÃO; GAMERO, 2009). Assim, Ana Cláudia Cury Calia de Souza-Luz e Vera Lúcia Lopes Cristovão (2017) apontam que a compreensão de concepção de linguagem é essencial para elaborarmos um adequado Plano de Ensino - relacionando criticamente os objetivos a serem atingidos -, já que exerce um papel norteador dos elementos que influenciam o plano pedagógico do professor, reportando ao processo de ensino e aprendizagem de línguas que se baseiam no conceito de linguagem. As três concepções de linguagem, de acordo com Souza-Luz e Cristovão (2017), são: a) linguagem como expressão do pensamento; b) linguagem como instrumento de comunicação; e c) linguagem como forma de interação.

As autoras destacam a relevância da linguagem como forma de interação, em sua natureza dialógica, sob a perspectiva bakhtiniana, pois o que é ensinado em sala de aula e o que os alunos aprendem está relacionado à concepção de linguagem do professor. A maneira como ensinamos a língua reflete a maneira como compreendemos a linguagem. Por isso, no ensino de LI para crianças, precisamos (re)pensar sua importância, e, aqui, damos atenção especial à linguagem visual, pois mesmo que a criança ainda não faça uso da língua escrita, ela pode interagir com o texto na modalidade visual. De acordo com Silvio Profirio da Silva (2014), a imagem é:

[...] concebida não como um mero recurso de entretenimento ou de decoração. Pelo contrário, concebemos a imagem como uma modalidade textual, que traz consigo inúmeras possibilidades de construção de significados por parte da criança. Cores, formas, formatos, tamanhos e até mesmo mensagens são aspectos advindos da imagem e que podem ser alçados à perspectiva de recursos, por meio dos quais a criança pode atribuir significado (SILVA, 2014, p. 88). 
Nos tópicos a seguir, abordaremos mais detalhadamente questões relacionadas à linguagem visual e as suas inúmeras possibilidades de construção de significados no ensino de LI na Educação Infantil por meio do letramento digital e multiletramentos. As autoras Vera Lúcia Lopes Cristovão e Raquel Gamero (2009) trazem suas contribuições sobre o agir com a linguagem e a importância do brincar na educação infantil:

O agir com a linguagem na educação infantil é um agir voltado para o lúdico - a brincadeira, o jogo, a vivência social de experiências, que promovem a aprendizagem. É na brincadeira que a aprendizagem ocorre e possibilita o desenvolvimento (CRISTOVÃO; GAMERO, 2009, p. 242).

As autoras sustentam a tese de que "brincar/jogar é o gênero de atividade central e imprescindível da educação infantil". Considerando que os gêneros textuais são instrumentos fundamentais para a realização do agir com a linguagem, para elas "alguns gêneros que circulam na infância tanto na esfera cotidiana quanto na escolar podem ser histórias infantis, cantigas de roda, canções, rimas, parlendas, instruções/regras de jogo, entre outros" (2009, p. 231).

\section{Letramento digital e Multiletramentos}

Não há dúvidas de que, na contemporaneidade, as práticas de leitura e escrita, na grande maioria, estão sendo mediadas por uma tecnologia digital (COSCARELLI; RIBEIRO, 2011; REZENDE, 2016). Sendo assim, pensar em letramento, atualmente, exige considerar a presença de tecnologias digitais em nossas práticas sociais. $\mathrm{O}$ letramento digital refere-se a uma ampliação de possibilidades de contato com a leitura e a escrita em um ambiente digital. Faz-se necessário esclarecer que, ao citarmos letramento digital, não estamos apenas nos referindo ao aprendizado da digitação e/ou manuseio de um computador ou similares, mas, sim, em saber localizar e selecionar materiais por meio de navegadores, entre outros. David Buckingham (2010, p. 49) declara que letramento digital vai além da questão funcional e instrumental, a criança precisa "ser capaz de avaliar e usar informação de forma crítica se quiser transformá-la em conhecimento".

Marcelo El Khouri Buzato (2007) afirma que, para que sejamos digitalmente letrados - professores e alunos -, é preciso que nos apropriemos da tecnologia, crítica e 
criticamente, dando significado e função ao invés de consumi-la passivamente ou de nos deixarmos ser consumidos por ela. Ainda de acordo Buzato:

Letramentos digitais (LDs) são conjuntos de letramentos (práticas sociais) que se apoiam, entrelaçam, e apropriam mútua e continuamente por meio de dispositivos digitais para finalidades específicas, tanto em contextos socioculturais geograficamente e temporalmente limitados, quanto naqueles construídos pela interação mediada eletronicamente (BUZATO, 2007, p. 16).

Maria Vidotti Rezende (2016), no artigo “O conceito de letramento digital e suas implicações pedagógicas", baseado em sua tese de doutorado, também traz contribuições para refletirmos sobre o conceito de letramento digital, não apenas acrescido letramento + tecnologia, mas, sim, de um letramento digital que afeta e é afetado por intermédio das culturas e conteúdos aos quais são introduzidos. Ressalta que seus efeitos, tanto sociais quanto cognitivos, são variáveis em função dos contextos socioculturais e das finalidades envolvidas no decorrer da sua apropriação:

\footnotetext{
Outra concepção que criticamos refere-se ao entendimento de que o letramento digital acrescenta ao conceito de letramento o uso da tecnologia. Essa percepção, apesar de simplista, não pode ser desconsiderada, ou seja, se letramentos são práticas sociais de uso da escrita e da leitura que têm sentidos específicos, finalidades específicas (dimensão social) e que demandam o domínio da escrita e da leitura (dimensão individual), os letramentos digitais podem ser conceituados da mesma forma, considerando-se a demanda das tecnologias digitais (REZENDE, 2016, p.103).
}

A partir das citações mencionadas, ficam claros o conceito e a importância do letramento digital, tanto na adaptação de uma tecnologia quanto no exercício efetivo das práticas de leitura e escrita no meio digital, ressaltando que "letrar" está no âmbito da prática social.

Ao falarmos de educação e tecnologia, não poderíamos deixar de citar as reflexivas contribuições do professor José Moran (2015), segundo o qual estamos diante das profundas mudanças na educação, e a escola precisa rever seus currículos, suas metodologias, seu tempo e seus espaços, a fim de "que todos aprendam de forma competente a conhecer, a construir seus projetos de vida e a conviver com os demais" (2015, p. 15). Ainda de acordo com esse autor, a tecnologia proporciona a interação entre todos os tempos e espaços, numa ligação entre o mundo físico e o digital. Esse 
movimento é caracterizado como "ensino híbrido", que é a integração dos espaços físicos da escola com os ambientes virtuais; a sala de aula com as tecnologias digitais.

Neste contexto digital, no qual estamos inseridos, segundo Rojo (2013), não há como dissociar o letramento do mundo moderno, pois esse se amplia a partir da compreensão das novas mídias e está ligado a dois tópicos importantes: a multiplicidade de cultura - resultante de uma sociedade multiétnica e multifacetada -, e a multiplicidade de semiose - processo de significação e produção de significados. Ligado ao letramento digital está o tema relacionado aos multiletramentos e às multimodalidades, tópicos que abordaremos a seguir.

De maneira a acompanhar o avanço do letramento digital, o Currículo do Estado de São Paulo, documento orientador da Educação Básica nas escolas dos municípios e do Estado de São Paulo, apresenta:

[...] um enfoque baseado nos multiletramentos, que consistem no entrelaçamento de diferentes semioses e linguagens verbais, visuais, corporais e audiovisuais, em um contínuo processo de significação contextualizado e dialógico, dando visibilidade à Língua Inglesa como facilitadora e determinante para a compreensão e socialização universal (SÃO PAULO, 2018, p. 764).

Como observamos, o Currículo do Estado de São Paulo propõe combinar as diferentes linguagens e atividades multidisciplinares que viabilizam a construção de uma representação não linear do conhecimento, tendo em vista que os multiletramentos vão além do letramento alfabético.

Para exemplificarmos os conceitos de multiletramentos e multimodalidades, tomaremos como ponto de partida os estudos de Rojo, que tem se dedicado a questões relacionadas à educação linguística, com destaque para pesquisas sobre práticas de leitura e escrita em contexto das mídias digitais.

Rojo (2013) diferencia "letramentos múltiplos" de "multiletramentos". Segundo a autora, o primeiro diz respeito à multiplicidade e variedade das práticas letradas, valorizadas ou não na sociedade. Já os multiletramentos apresentam dois tipos específicos: a multiplicidade cultural da população - cultura popular versus erudita, central versus marginal, canônica versus de massa -; e a multiplicidade semiótica e/ou multimodalidade, que é a construção de textos por meio dos quais os sujeitos se informam e se comunicam. Textos compostos por diversas linguagens, que vão além da 
escrita manual e impressa, até áudio, vídeo, tratamento de imagens, edição e diagramação.

Silva (2014) reforça a teoria de que o texto, em sua mais ampla definição, vem adquirindo novas configurações que ultrapassam as palavras e frases, assumindo assim uma condição multimodal, apresentando diferentes modos de leitura. Ainda sobre multiletramentos, em Cenários futuros para as escolas, Rojo os define como:

[...] práticas de trato com os textos multimodais ou multissemióticos contemporâneos - majoritariamente digitais, mas também digitais impressos - que incluem procedimentos (como gestos para ler, por exemplo) e capacidades de leitura e produção que vão muito além da compreensão e produção de textos escritos, pois incorporam a leitura e (re)produção de imagens e fotos, diagramas, gráficos e infográficos, vídeos, áudio etc. (ROJO, 2013, p. 21).

Rojo, em Pedagogia dos Multiletramentos, esclarece a funcionalidade dos multiletramentos por meio de várias habilidades e competências linguísticas:

\footnotetext{
Em qualquer dos sentidos da palavra "multiletramentos" - no sentido da diversidade cultural de produção e circulação dos textos ou no sentido da diversidade de linguagens que os constituem -, os estudos são recorrentes em apontar para eles algumas características consideradas importantes: eles são interativos; mais que isso, eles são colaborativos; eles fraturam e transgridem as relações de poder estabelecidas, em especial as relações de propriedade (das máquinas, das ferramentas, das ideias, dos textos (verbais ou não); eles são híbridos, fronteiriços, mestiços (de linguagens, modos, mídias e culturas) (ROJO, 2013, p. 10).
}

Atualmente, produzimos uma infinidade de textos multimodais, mesmo que involuntariamente, ao utilizarmos imagens estáticas, imagens em movimentos, escrita e som. Esses diversos tipos de textos são postados nas redes sociais, ambiente em que a maioria das crianças e adolescentes estão inseridos. Nestas postagens, percebemos uma possibilidade de participação interativa e crítica do interlocutor, construindo significados a partir da vivência social.

Observamos que a maior parte da nossa experiência cotidiana de representação é intrinsecamente multimodal, levando-nos a compreender que a escola precisa adequar o projeto de LI para que o texto escrito não seja o predominante. Estamos falando de situações reais de escrita, considerando que o aluno, na era midiática, tenha contato e 
leia muito mais textos armazenados nas páginas da web, compreendendo textos formados por vários aspectos modais - visual, escrito e som.

Conforme já explicitado acerca do texto na condição multimodal, notamos a importância de atrelar as multimodalidades ao ensino de LI na Educação Infantil. Silva destaca que:

[...] as instituições de ensino voltadas para a infância podem contribuir, de forma significativa, para o desenvolvimento da criança a partir da promoção de práticas plurais de leituras. Tudo isso contribui não só para a construção social do conhecimento da criança, mas, sobretudo, para a formação da sua identidade (SILVA, 2014, p. 82).

Ressaltamos, de acordo com Silva, que a construção social do conhecimento da criança ocorre a partir "dos vínculos estabelecidos entre ela e as experiências ocorridas nas suas práticas cotidianas" (2014, p. 89). Sendo assim, ao falarmos do ensino e aprendizagem de LI para a Educação Infantil e de suas práticas comunicativas, é necessário que façamos uma síntese da concepção do Inglês como língua franca, já que esse é um dos pilares da BNCC.

\section{Inglês como Língua Franca (ILF)}

De acordo com Diego Balzanello e Fábio Henrique Rosa Senefonte (2016), pesquisas contemporâneas sugerem que a língua não deve ser usada apenas para servir à cultura-alvo, mas, sim, para possibilitar que o aprendiz se torne um cidadão global, ativo e crítico em sua comunidade local. Para tanto, não é possível considerar apenas o ensino de uma língua restritamente voltado ao conhecimento linguístico.

A disseminação da Língua Inglesa no mundo tem transformado seu papel e ocasionado mudanças no ensino. De fato, estamos diante de uma nova visão pósmoderna para o aprendizado da Língua Inglesa, que é a compreensão do Inglês como língua franca (ILF), termo geralmente utilizado para representar o uso da língua por indivíduos não nativos (DUBOC, 2019).

Há diversas pesquisas sendo desenvolvidas acerca do conceito de ILF, campo centrado na linguística aplicada. Nesse sentido, uma definição até então bem aceita é a de que "qualquer uso do inglês entre falantes de diferentes línguas maternas para quem ele é o meio de comunicação escolhido, e frequentemente, a única opção" 
(SEIDLHOFER, 2011, p. 7). Dessa forma, é plausível considerarmos o ILF sob uma perspectiva comunicativa.

As autoras brasileiras Telma Gimenez, Luciana Cabrini Simões Calvo e Michele Sales El Kadri (2011) definem o ILF como:

[...] um sistema linguístico adicional que serve como meio de comunicação entre falantes de diferentes línguas maternas, ou uma língua pela qual os membros de diferentes comunidades de fala podem se comunicar entre si, mas que não é a língua materna de nenhum deles- uma língua que não tem falantes nativos (GIMENEZ; CALVO; EL KADRI, 2011, p. 7).

Voltando aos aspectos relacionados ao ensino, a BNCC (BRASIL, 2017) apresenta o conceito de Inglês como língua franca e aborda o ensino de LI de maneira a combater os preconceitos linguísticos e, consequentemente, os sociais:

\footnotetext{
Nessa proposta, a língua inglesa não é mais aquela do "estrangeiro", oriundo de países hegemônicos, cujos falantes servem de modelo a ser seguido, nem tampouco trata-se de uma variante da língua inglesa. Nessa perspectiva, são acolhidos e legitimados os usos que dela fazem falantes espalhados no mundo inteiro, com diferentes repertórios linguísticos e culturais, o que possibilita, por exemplo, questionar a visão de que o único inglês "correto" e a ser ensinado - é aquele falado por estadunidenses ou britânicos. (BRASIL, 2017, p. 241).
}

Diante do exposto, objetiva-se refletir sobre a necessidade de proporcionar aos alunos um ambiente de aprendizagem que lhes ofereça real interação, ou melhor, que os estudantes sejam colocados em situações reais de práticas linguísticas. Dessa forma, o educador deve estar atento aos eixos estruturantes das práticas pedagógicas, campos de experiências, grupos etários e objetivos de aprendizagem e de desenvolvimento.

A seguir, apresentaremos uma proposta de inserção de letramento digital com base na BNCC (BRASIL, 2017).

\section{BNCC PARA O ENSINO INFANTIL: UMA PROPOSTA PARA A INSERÇÃO DO LETRAMENTO DIGITAL}

A BNCC (BRASIL, 2017) assegura, por meio dos eixos estruturantes das práticas pedagógicas e das competências gerais da Educação Básica, seis direitos de aprendizagem e de desenvolvimento na Educação Infantil que fortalecem as condições 
de aprendizado, tencionando que as crianças "possam desempenhar um papel ativo em ambientes que as convidem a vivenciar desafios e a sentirem-se provocadas a resolvêlos, nas quais possam construir significados sobre si, os outros e o mundo social e natura" (BRASIL, 2017. p. 37).

Os direitos de aprendizagem e de desenvolvimento na Educação Infantil, de acordo com a BNCC (2017, p. 18), são apresentados a seguir, no Quadro 1:

\section{Quadro 1 - Direitos de Aprendizagem}

\begin{tabular}{|c|c|c|}
\hline $\begin{array}{l}\text { * Conviver com outras } \\
\text { crianças e adultos, em } \\
\text { pequenos e grandes grupos, } \\
\text { utilizando diferentes } \\
\text { linguagens, ampliando o } \\
\text { conhecimento de si e do outro, } \\
\text { o respeito em relação à cultura } \\
\text { e às diferenças entre as } \\
\text { pessoas. }\end{array}$ & $\begin{array}{l}\text { * Brincar cotidianamente de } \\
\text { diversas formas, em diferentes } \\
\text { espaços e tempos, com } \\
\text { diferentes parceiros (crianças e } \\
\text { adultos), ampliando e e } \\
\text { diversificando seu acesso a } \\
\text { produções culturais, seus } \\
\text { conhecimentos, sua } \\
\text { imaginação, sua criatividade, } \\
\text { suas experiências emocionais, } \\
\text { corporais, sensoriais, } \\
\text { expressivas, cognitivas, sociais } \\
\text { e relacionais. }\end{array}$ & $\begin{array}{l}\text { *articipar ativamente, com } \\
\text { adultos e outras crianças, tanto do } \\
\text { planejamento da gestão da escola e } \\
\text { das atividades propostas pelo } \\
\text { educador quanto da realização das } \\
\text { atividades da vida cotidiana, tais } \\
\text { como a escolha das brincadeiras, } \\
\text { dos materiais e dos ambientes, } \\
\text { desenvolvendo } \\
\text { linguagens e elaborando } \\
\text { conhecimentos, decidindo e se } \\
\text { posicionando. }\end{array}$ \\
\hline $\begin{array}{l}\text { Explorar movimentos, } \\
\text { gestos, sons, formas, texturas, } \\
\text { cores, palavras, emoções, } \\
\text { transformações, } \\
\text { relacionamentos, histórias, } \\
\text { objetos, elementos da } \\
\text { natureza, na escola e fora } \\
\text { dela, ampliando seus saberes } \\
\text { sobre a cultura, em suas } \\
\text { diversas modalidades: as } \\
\text { artes, a escrita, a ciência e a } \\
\text { tecnologia. }\end{array}$ & $\begin{array}{l}\text { *xpressar, como sujeito } \\
\text { dialógico, criativo e sensível, } \\
\text { suas necessidades, emoções, } \\
\text { sentimentos, } \\
\text { hipóteses, dúvidas, } \\
\text { opiniões, questionamentos, por } \\
\text { meio de diferentes linguagens. }\end{array}$ & $\begin{array}{l}\text { *onhecer-se e construir sua } \\
\text { identidade pessoal, social e cultural, } \\
\text { constituindo uma imagem positiva } \\
\text { de si e de seus grupos de } \\
\text { pertencimento, nas diversas } \\
\text { experiências de cuidados, } \\
\text { interações, brincadeiras e linguagens } \\
\text { vivenciadas na instituição escolar e } \\
\text { em seu contexto familiar e } \\
\text { comunitário. }\end{array}$ \\
\hline
\end{tabular}

Fonte: Dados organizados pelas pesquisadoras a partir de (BRASIL, 2017).

A organização curricular da BNCC (BRASIL, 2017) na Educação Infantil está estruturada em cinco campos de experiência, em que são definidos os objetivos de aprendizagem e de desenvolvimento, além de enfatizar noções, habilidades, atitudes, valores e afetos. Estes campos são: "O eu, o outro e nós"; "Corpo, gestos e movimentos"; "Traços, sons, cores e formas"; "Oralidade e escrita"; "Espaços, tempos, quantidades, relações e transformações".

Destaca-se também, de acordo com o documento, a importância de reconhecer as especificidades dos diferentes grupos etários que constituem a etapa da Educação 
Infantil. São organizados em três grupos. Na creche, bebês - zero a 1 ano e 6 meses - e crianças bem pequenas - 1 ano e 7 meses a 3 anos e 11 meses. Na Pré-escola, crianças pequenas -4 anos a 5 anos e 11 meses.

É de suma relevância estar atento à organização curricular da BNCC a fim de compreender o que realmente promove a aprendizagem e o desenvolvimento nos diversos campos de experiências, levando sempre em consideração as brincadeiras e interações como eixos estruturantes.

\section{PROCEDIMENTOS METODOLÓGICOS}

A fim de atingir o objetivo proposto, realizamos uma pesquisa qualitativa, pois, de acordo com Mirian Goldenberg (2004), nessa abordagem, "a preocupação do pesquisador não é com a representatividade numérica do grupo pesquisado, mas com o aprofundamento da compreensão de um grupo social, de uma organização, de uma instituição, de uma trajetória" (p. 14).

Assim, este artigo foi elaborado considerando alguns dados obtidos na pesquisa, apresentando duas etapas: uma de revisão bibliográfica e outra de elaboração do Plano Anual de Ensino da Educação Infantil. Na primeira etapa, por meio de revisão bibliográfica, buscamos identificar a importância e a forma de se desenvolver o letramento digital na Educação Básica, além de refletirmos sobre a sua contribuição para a construção do conhecimento e a formação identitária do aluno. Para tanto, realizamos um levantamento bibliográfico a respeito do Ensino de Inglês na Educação Infantil a partir das contribuições do Guia Curricular para Língua Inglesa (2013); Parâmetros Curriculares Nacionais de Língua Inglesa (1998); Pereira e Lopes (2005); Pereira e Peruzza (2002); Barbosa et al (2014); Cristovão e Gamero (2009); e Silva (2014).

Debruçamo-nos também sobre questões relacionadas ao letramento digital, multiletramentos e, consequentemente, sobre o exercício docente ligado às práticas pedagógicas digitais e formação continuada de professores. Para tal, nos embasamos em Coscarelli e Ribeiro (2011); Rezende (2016); Buzato (2007); Moran (2015); Rojo (2013, 2019); e no Currículo do Estado de São Paulo (2018). Para compreendermos o Inglês como língua franca e as práticas de linguagem pelo viés comunicativo, 
analisamos algumas produções de Balzanello e Senefonte (2016); Dulboc (2019); Seidlhofer (2011); Gimenez, Calvo e El Kadri (2011); e Base Nacional Comum Curricular - BNCC (BRASIL, 2017).

Finalizando a primeira etapa, realizamos um breve estudo sobre os eixos estruturantes das práticas pedagógicas, sobre as competências gerais da Educação Básica e sobre os direitos de aprendizagem e de desenvolvimento na Educação Infantil, com sugestões de atividades, utilizando o letramento digital de acordo com as competências da BNCC.

Na segunda etapa deste trabalho, ocorreu a elaboração do Plano Anual de Ensino da Educação Infantil. Desse modo, foi realizada uma reunião coletiva com aproximadamente vinte e cinco professores da rede municipal de ensino com a coordenadora da Secretaria Municipal de Educação e com a supervisora do departamento de Língua Inglesa. Todavia, a estratégia de reunir uma grande quantidade de professores não foi a mais adequada para surtir o efeito e o rendimento esperados. Assim, foram realizados alguns ajustes na dinâmica das reuniões, no sentido de serem organizadas com periodicidade semanal, com rodízio de quatro professores por vez durante duas horas. O material de suporte pedagógico - baseado na BNCC e no Currículo Paulista - foi finalizado e tem como objetivo geral contemplar os direitos de aprendizagem e de desenvolvimento das crianças.

\section{PROTÓTIPO DE PLANO DE ENSINO E EXEMPLO DE ATIVIDADE}

Apresentaremos a seguir um quadro-modelo do Plano de Ensino - elaborado coletivamente com os professores da rede municipal de ensino e ajustado pelas pesquisadoras - para trabalharmos com crianças da segunda Etapa do Ensino Infantil. No item "Prática de vocabulário", podemos abordar palavras e introduzir frases que fazem parte do dia a dia da criança em sala de aula e fora dela. Ressaltamos que estamos pautados na abordagem comunicativa voltada às práticas sociais. $\mathrm{Na}$ coluna sobre “Convivência", tentamos articular com a "Prática de vocabulário", observando algumas temáticas que podem ser introduzidas, como, por exemplo, pluralidade cultural, saúde e 
ética, organização, respeito etc. Na última coluna, algumas possíveis "Situações de Aprendizagem".

Quadro 2 - Plano de Ensino - 2019 - Crianças pequenas - $2^{\text {a }}$ Etapa

\begin{tabular}{|c|c|c|}
\hline ICA DE VOCABULÁRIO & CONVIVÊECIA & $\begin{array}{c}\text { SITUAÇÕES DE } \\
\text { APRENDIZAGEM }\end{array}$ \\
\hline $\begin{array}{l}\text { Open your notebook/ Close your } \\
\text { notebook. } \\
\text { Celebrate: Easter / Valentine's } \\
\text { Day, } \\
\text { Means of transportation: airplane, } \\
\text { bike, car, truck, bus, motorcycle, } \\
\text { train. } \\
\text { Face expressions: happy, angry, } \\
\text { sad, sleepy, hungry, sick, bored. } \\
\text { Celebrate: June party / Mother's } \\
\text { Day. } \\
\text { A birthday party: chocolate cake, } \\
\text { presents, balloons, party hat, } \\
\text { candle/ Thank you. } \\
\text { Food party: sandwich, cake, hot } \\
\text { dog, pizza, water, juice, coke, } \\
\text { hamburger, ice-cream, candy. } \\
\text { - Celebrate: Father's Day } \\
\text { Let's play: volleyball, play soccer, } \\
\text { swim, basketball, play tennis, } \\
\text { dance, jump. }\end{array}$ & $\begin{array}{l}\text { - Proporcionar aos alunos a aquisição de } \\
\text { vocabulário básico, articulado às } \\
\text { estruturas da língua inglesa, a partir de } \\
\text { palavras relacionadas à realidade } \\
\text { imediata deles. } \\
\text { - Enfatizar as datas comemorativas, } \\
\text { trabalhando aspectos culturais. } \\
\text { - Despertar imaginação e criatividade. } \\
\text { - Trazer elementos voltados à } \\
\text { pluralidade cultural: cumprimentos em } \\
\text { inglês - possibilidade de discutir as } \\
\text { diferenças culturais nas formas de } \\
\text { cumprimentos. } \\
\text { - Cuidar de si mesmo e respeito ao } \\
\text { próximo - reflexão sobre a relevância da } \\
\text { atividade física apropriada para criança } \\
\text { e do respeito ao outro e suas } \\
\text { adversidades. } \\
\text { devem ser valorizadas, todo profissional } \\
\text { tem seu valor e desempenha papel } \\
\text { importante dentro da sociedade. } \\
\text { - Aprender a ter organização e cuidado } \\
\text { com os objetos escolares. Saber } \\
\text { respeitar o outro e saber dividir durante } \\
\text { as competições e brincadeiras. } \\
\text { - Valonprometer a alegria. } \\
\text { - Refletir sobre o costume de } \\
\text { comemorar o aniversário - explorar } \\
\text { aspectos da festa (bolo, presente, } \\
\text { convidados...). }\end{array}$ & $\begin{array}{l}\text {-Warm-up, atividades } \\
\text { que despertam o } \\
\text { interesse pelos } \\
\text { estudos do novo } \\
\text { assunto de modo } \\
\text { lúdico e motivador. } \\
\text { - Prática oral do } \\
\text { vocabulário por meio } \\
\text { de histórias, músicas, } \\
\text { rodas de conversa e } \\
\text { gestos. } \\
\text { - Atividade de escrita } \\
\text { que desenvolva as } \\
\text { habilidades motoras e } \\
\text { estimulem a } \\
\text { criatividade a } \\
\text { mesmo tempo em que } \\
\text { reforçam a a } \\
\text { aprendizado. } \\
\text { - Brincadeiras que } \\
\text { contribuam para a } \\
\text { apreensão a do } \\
\text { vocabulário estudado. } \\
\text { - Discussão sobre } \\
\text { dospeitar o momento } \\
\text { dos colegas. }\end{array}$ \\
\hline
\end{tabular}

Fonte: Dados organizados pelas pesquisadoras (2021).

Das dez competências definidas pela BNCC (BRASIL, 2017), destacaremos cinco delas, seguidas de sugestões de temas possíveis de serem abordados na Educação 
Infantil a partir do uso de recursos digitais. Ressaltamos que as competências ligadas ao ensino de LI foram formuladas em reunião de Replanejamento Escolar juntamente com a equipe da editora Macmillan education, que é responsável, atualmente, pelo fornecimento dos livros didático Spaghetti Kids, utilizados na rede municipal de ensino do primeiro ao quinto ano.

No quadro 3, a seguir, colocaremos em evidência as competências estabelecidas pela BNCC (BRASIL, 2017), conciliadas ao ensino de LI para crianças, com sugestões de temas ou atividades, ressaltando que, como estamos lidando com crianças bem pequenas, na faixa etária entre quatro e seis anos, o uso de recursos tecnológicos, em algumas ocasiões, vai servir para despertar o interesse pelo assunto estudado, já que tais recursos permitem colocar a criança em contato com filmes, músicas, imagens em movimento, etc. Em outros momentos, a criança vai iniciar tarefas, utilizando a tecnologia quando, por exemplo, brinca com jogos on-line - jogo da memória, quebra cabeça, mistura de cores, etc.

Quadro 3 - Competências estabelecidas e conciliadas no uso de recursos digitais

\begin{tabular}{|c|c|c|}
\hline Competências estabelecidas pela BNCC & $\begin{array}{l}\text { Competências da BNCC } \\
\text { conciliadas ao ensino de LI }\end{array}$ & $\begin{array}{l}\text { Sugestões } r \text { de } \\
\text { temas/atividade com uso } \\
\text { de recursos digitais: lousa } \\
\text { digital, computador, e } \\
\text { internet }\end{array}$ \\
\hline $\begin{array}{l}\text { 1. Conhecimento } \\
\text { Valorizar e utilizar os conhecimentos } \\
\text { historicamente construídos sobre o mundo } \\
\text { físico, social, cultural e digital para } \\
\text { entender e explicar a realidade, continuar } \\
\text { aprendendo e colaborar para a construção } \\
\text { de uma sociedade justa, democrática e } \\
\text { inclusiva. }\end{array}$ & $\begin{array}{l}\text { Identificar o lugar de si } \\
\text { mesmo e o do outro, em um } \\
\text { mundo plurilíngue e } \\
\text { multicultural, refletindo } \\
\text { sobre como a aprendizagem } \\
\text { da LI contribui para a } \\
\text { inserção do aluno no mundo } \\
\text { globalizado. }\end{array}$ & $\begin{array}{l}\text { Greetings. } \\
\text { Family: } \\
\text { finger/shark/duck/cow... } \\
\text { Nature: The Sun, flower, } \\
\text { tree, moon, star... } \\
\text { Suggestions: Nursery } \\
\text { rhymes, stories, Fairy tales. }\end{array}$ \\
\hline $\begin{array}{l}\text { 2. Pensamento Científico, Crítico e } \\
\text { Criativo. } \\
\text { Exercitar a curiosidade intelectual e } \\
\text { recorrer à abordagem própria das ciências, } \\
\text { incluindo a investigação, a reflexão, a } \\
\text { análise crítica, a imaginação e a } \\
\text { criatividade, para investigar causas, } \\
\text { elaborar e testar hipóteses, formular e } \\
\text { resolver problemas e criar soluções. }\end{array}$ & $\begin{array}{l}\text { Comunicar-se na LI por } \\
\text { meio do uso variado de } \\
\text { linguagens em mídias } \\
\text { impressas ou digitais, } \\
\text { ampliando as perspectivas e } \\
\text { possibilidades para a } \\
\text { compreensão dos valores e } \\
\text { interesses de outras culturas. }\end{array}$ & $\begin{array}{l}\text { Colors: memory game/CD } \\
\text { Learn English Kids - What } \\
\text { color is it? } \\
\text { Five mistake game. } \\
\text { Activities: coloring, match, } \\
\text { point out. }\end{array}$ \\
\hline $\begin{array}{l}\text { 3. Repertório Cultural } \\
\text { Valorizar e fruir as diversas manifestações } \\
\text { artísticas e culturais, das locais às } \\
\text { mundiais, e também participar de práticas }\end{array}$ & $\begin{array}{l}\text { Ser exposto a similaridades e } \\
\text { diferenças entre a LI e a } \\
\text { língua materna, articulando- } \\
\text { as a aspectos sociais, } \\
\text { culturais e identitários em } \\
\text { uma relação intrínseca entre }\end{array}$ & $\begin{array}{l}\text { Introducing yourself and } \\
\text { friends. } \\
\text { Classroom commands. }\end{array}$ \\
\hline
\end{tabular}




\begin{tabular}{|c|c|c|}
\hline $\begin{array}{l}\text { diversificadas da produção artístico- } \\
\text { cultural. }\end{array}$ & língua, cultura e identidade. & $\begin{array}{l}\text { Valentine's Day, Mother's } \\
\text { Day, Father's Day } \\
\text { Halloween, Thanksgiving, } \\
\text { Christmas. }\end{array}$ \\
\hline $\begin{array}{l}\text { 4. Comunicação } \\
\text { Utilizar diferentes linguagens - verbal } \\
\text { (oral ou visual-motora, como Libras, e } \\
\text { escrita), corporal, visual, sonora e digital -, } \\
\text { bem como conhecimentos das linguagens } \\
\text { artística, matemática e científica, para se } \\
\text { expressar e partilhar informações, } \\
\text { experiências, ideias e sentimentos em } \\
\text { diferentes contextos. }\end{array}$ & $\begin{array}{l}\text { Ser exposto a repertórios } \\
\text { linguístico-discursivos da } \\
\text { língua inglesa, usados em } \\
\text { diferentes países e por } \\
\text { grupos sociais distintos } \\
\text { dentro de um mesmo país, } \\
\text { valorizando os usos } \\
\text { heterogêneos, híbridos e } \\
\text { multimodais emergentes nas } \\
\text { escolas contemporâneas. }\end{array}$ & $\begin{array}{l}\text { School objects. } \\
\begin{array}{l}\text { Getting Ready for School } \\
\text { song. }\end{array} \\
\begin{array}{l}\text { Numbers/Alphabet rhymes } \\
\text { Nursery } \\
\text { numbers/alphabet. }\end{array} \\
\begin{array}{l}\text { Memory game, CD or on- } \\
\text { line. }\end{array}\end{array}$ \\
\hline $\begin{array}{l}\text { 5. Cultura Digital } \\
\text { Compreender, utilizar e criar tecnologias } \\
\text { digitais de informação e comunicação de } \\
\text { forma crítica, significativa, reflexiva e ética } \\
\text { nas diversas práticas sociais para se } \\
\text { comunicar, acessar e disseminar } \\
\text { informações, produzir conhecimentos, } \\
\text { resolver problemas e exercer } \\
\text { protagonismo. }\end{array}$ & $\begin{array}{l}\text { Utilizar novas tecnologias, } \\
\text { com novas linguagens e } \\
\text { modos de interação, para } \\
\text { pesquisar, selecionar, } \\
\text { compartilhar, posicionar-se e } \\
\text { produzir sentidos em } \\
\text { práticas de letramento na } \\
\text { língua inglesa, de forma } \\
\text { ética e responsável. }\end{array}$ & $\begin{array}{l}\text { Interactive stories } \\
\text { Song } \\
\text { Fairy tales } \\
\text { Comics } \\
\text { Illustrative images. }\end{array}$ \\
\hline
\end{tabular}

Fonte: Adaptado pelas pesquisadoras (2021).

Exemplo de atividade para a Educação Infantil com uso das tecnologias digitais

Story - Three Little Pigs

Após a contação de história, em Língua Inglesa, por meio do livro impresso, é interessante introduzir algumas palavras, seja através de fantoches, brincadeira ou desenhos. Utilizando a lousa digital, apresentar aos alunos a história de forma cantada, explorando o visual e listening (site: https://www.youtube.com/watch?v=2s7cz6p7jew). O professor pode montar um memory game usando o Power Point (Dicas para criar memory game: site https://www.youtube.com/watch?v=rvm0q-vNVEI). A escolha das imagens fica a critério do professor, podendo ser Wolf, Three Little Pigs, door, house sticks, bricks and straw, chimney. Este tipo de atividade pode ser realizada com histórias diversas. Alguns sites de fácil acesso com Nursery rhymes são: Cocomelon, uspstudios.co, babytv, learn English Kids.

Fonte: Elaborada pelas pesquisadoras (2021).

Desse modo, exemplos de atividades como Story - Three Little Pigs possibilitam múltiplas relações de interações, sejam com o conteúdo e as informações; com os recursos multimodais; ou com os professores e os colegas de classe, permitindo, assim, que o aluno seja um agente ativo em suas práticas dentro e fora da sala de aula.

\section{CONSIDERAÇÕES FINAIS}


Este artigo pretendeu apresentar a proposição de um planejamento - com temas para atividades - com base nas competências da BNCC (BRASIL, 2017) e com foco no desenvolvimento de letramento digital para crianças da segunda etapa do Ensino Infantil. A leitura desse documento nos levou à reflexão sobre como utilizar a tecnologia de forma crítica e responsável, bem como sobre o que é, como se efetivam o letramento digital, os multiletramentos e a multimodalidade.

Para tais indagações, tornaram-se imprescindíveis as contribuições de Pereira e Peruzza (2002); Pereira e Lopes (2005) e Barbosa et al (2014) ao contribuírem com pesquisas que ressaltam a importância de ferramentas tecnológicas educacionais na Educação Infantil e software educativos, visto que ampliam a possibilidade de formar cidadãos mais criativos. Silva (2014) esclarece muitas dúvidas sobre o texto na modalidade visual e suas inúmeras possibilidades de construção de significados. Cristovão e Gamero (2009) destacam a importância do agir com a linguagem e o brincar na educação Infantil. A partir dessas teorias, dentre outras, tornou-se possível a elaboração do Plano de Ensino para a Educação Infantil - Maternal II, $1^{a} e 2^{a}$ etapas.

Como citado no início deste artigo, a escola em que uma das pesquisadoras leciona possui infraestrutura digital, possibilitando o frequente uso de recursos digitais nas aulas. Entretanto, percebemos que apenas a infraestrutura tecnológica não garante a exploração adequada desses recursos digitais se o professor não se sentir seguro para utilizá-los. Nesse sentido, a experiência relatada neste artigo nos mostrou a relevância de processos formativos que observem a problemática apresentada, ou seja, a especificidade da formação docente para atuar com ensino de Língua Inglesa para crianças na educação infantil. Após momentos de estudo e reflexão, foi possível compreender os nossos avanços com relação ao uso das tecnologias digitais, mas, em contrapartida, a ausência de um trabalho com sequências didáticas gerava certo desconforto, pois as aulas pareciam fragmentadas.

Para trabalhar numa perspectiva de uso da linguagem como prática social, foi necessário aceitar o desafio de elaborar um Plano de Ensino para a Educação Infantil, vinculado à BNCC (BRASIL, 2017), numa perspectiva de trabalho colaborativo com os demais professores da Rede de Ensino. Ressaltamos que as atividades propostas podem ser trabalhadas durante um ano letivo, todavia, a plena realização delas está atrelada a fatores condicionantes externos e/ou internos relativos à realidade de cada unidade 
escolar. A nossa intencionalidade é que a aprendizagem seja efetiva, a fim de colaborar para formação de um aluno crítico, responsável, criativo e autônomo.

Torna-se, portanto, urgente manter a discussão sobre a formação continuada de professores para o trabalho na perspectiva dos multiletramentos, considerando ainda as especificidades do profissional que ensina Língua Inglesa na Educação Infantil, para que ele se sinta motivado e preparado para acompanhar os avanços tecnológicos inerentes aos desafios do contexto atual.

\section{Referências}

ALMEIDA FILHO, José Carlos Paes de. Dimensões comunicativas no ensino de linguas. Campinas-SP: Pontes, 2008.

BALZANELlO, Diego; SENEFONTE, Fábio Henrique Rosa. Percepções de professores sobre o ensino de Língua Inglesa como Língua Franca em Sertanópolis. Rev. Claraboia, Jacarezinho, v. 6, p. 115-140, jul./dez., 2016.

BARBOSA, Gilvana Costa. et tal. Tecnologias digitais: Possibilidades e desafios na Educação Infantil. In: Congresso Brasileiro de Ensino Superior a Distância, 11, 2014, Florianópolis/SC. Anais [...] Florianópolis: UFSC, ago. 2014. p. 2888-2899.

BRASIL. Base Nacional Comum Curricular (BNCC): Educação Infantil e Ensino Fundamental. Brasília: MEC/Secretaria de Educação Básica, 2017. Disponível em: http://basenacionalcomum.mec.gov.br/images/BNCC_EI_EF_110518_versaofinal_site. pdf.

BRASIL. Secretaria de Educação Fundamental. Parâmetros Curriculares Nacionais: terceiro e quarto ciclos do ensino fundamental: língua estrangeira. Brasília: MEC/SEF, 1998. Disponível em: http://portal.mec.gov.br/seb/arquivos/pdf/pcn_estrangeira.pdf. Acesso em: 20 mai. 2019.

BUCKINGHAM, David. Cultura digital, educação midiática e o lugar da escolarização. Educação e Realidade, Porto Alegre, v. 35, n. 3, p. 37-58, 2010. Disponível em: http://seer.ufrgs.br/educacaoerealidade/article/view/13077/10270. Acesso em: 19 nov. 2019.

BUZATO, Marcelo El Khouri. Sobre a Necessidade de Letramento Eletrônico na Formação de Professores: O Caso Teresa. In: CABRAL, L. G; SOUZA, P.; LOPES, R. E.V. \& PAGOTTO, E. G. (org.) Linguística e Ensino: novas tecnologias. Blumenau: Nova Letra, 2001. p. 229-267. 
BUZATO, Marcelo El Khouri. Entre a Fronteira e a Periferia: Linguagem e Letramento na Inclusão Digital. 2007. 284p. Tese (Doutorado em Linguística Aplicada) - Instituto de Estudos da Linguagem, Universidade Estadual de Campinas, Campinas, 2007.

CELANI, Maria Antonieta Alba (org.). Professores e formadores em mudança: relato de um processo de reflexão e transformação da prática docente. Campinas, SP: Mercado de Letras, 2002.

COSCARELLI, Carla Viana; RIBEIRO, Ana Elisa. Letramento digital: aspectos sociais e possibilidades pedagógicas. 3. ed. Belo Horizonte: Ceale: Autêntica, 2011.

CRISTOVÃO, Vera Lúcia Lopes; GAMERO, Raquel. Brincar aprendendo ou aprender brincando? O inglês na infância. Trabalho em Linguística Aplicada, Campinas, v. 48. n. 2 p. 229-245, jul./dez. 2009.

DUBOC, Ana Paula Martinez. Falando francamente: uma leitura bakhtiniana do conceito de "inglês como língua franca" no componente curricular língua inglesa da BNCC. Revista da Anpoll, São Paulo, v. 1. n. 48. p. 10-22, 2019.

GIMENEZ, Telma. Trajetórias na formação de professores de Línguas. Londrina: Eduel, 2002.

GIMENEZ, Telma; CRISTOVÃO, Vera Lúcia Lopes. Derrubando paredes e construindo pontes: formação de professores de língua inglesa na atualidade. Rev. Brasileira de Línguistica Aplicada, Belo Horizonte, v. 4, n. 2, p. 85-95, 2004.

GIMENEZ, Telma; et al. Inglês como língua franca: desenvolvimentos recentes. Revista. Brasileira de Línguistica Aplicada [online], Belo Horizonte, v. 15, n. 3, p. 593619. Disponível em: http://www.scielo.br/pdf/rbla/v15n3/1984-6398-rbla-15-0300593.pdf. Acesso em: 24 set. 2019.

GIMENEZ, Telma; CALVO, Luciana Cabrini Simões; EL KADRI, Michele Sales. Inglês como Língua Franca: ensino-aprendizagem e formação de professores. Campinas: Pontes Editores, 2001.

GOLDENBERG, Mirian. A arte de pesquisar: como fazer pesquisa quantitativa em Ciências. 8. ed. Rio de Janeiro: Record, 2004.

GUIA Curricular para a Língua Inglesa. Educação Infantil e Fundamental. Subsídios para professores e gestores. Londrina, PR, 2013.

LEFFA, Vilson José. On becoming digitally literate: the production of computermediated materials by language teachers. In: Convenção da Associação dos Professores de Inglês do Rio Grande do Sul. Teaching and Learning Processes. Porto Alegre: PUCRS, 2005. 
MENEZES, Vera. A formação do professor para uso da tecnologia. In: SILVA, K. A. et al (org.). A formação de professores de línguas: Novos Olhares. v. 2. Campinas, SP: Pontes Editores, 2013. p. 209-230.

MORAN, José. Mudando a educação com metodologias ativas. In: SOUZA, C. A. de; MORALES, O. E. T. (orgs.). Coleção Mídias Contemporâneas, Convergências Midiáticas, Educação e Cidadania: aproximações jovens. v. II. PG: Foca FotoPROEX/UEPG, 2015, p. 15-33.

PEREIRA, Andréia Regina; LOPES, Roseli de Deus. Legal: Ambiente de autoria para Educação Infantil apoiada em meios Eletrônicos Interativos. In: Simpósio Brasileiro de Informática na Educação - SBIE, 16, 2005, Juiz de Fora. Anais [...] Juiz de Fora: UFJF, 2005. p. 23-30.

PEREIRA, Andréia Regina; PERUZZA, Ana Paula Piovesan Melchiori. Tecnologia de Realidade Virtual aplicada à Educação Pré-escolar. Simpósio Brasileiro de Informática na Educação - SBIE, 13, 2002, UNISINOS, 2002. p. 385-391.

REZENDE, Maria Vidotti. O conceito de Letramento digital e suas implicações pedagógicas. Revista Texto Livre. Minas Gerais, v. 9, n. 1, p. 94-107, 2016.

ROCHA, Luciana Caprice Silva Santos da. Formação de Professores na Educação Infantil. Revista. Projeção e Docência. v.3. n.1. p. 28-36, mar. 2012.

ROJO, Roxane. Cenários futuros para as escolas. Educação no Século XXI Multiletramentos. v.3. p. 19-22. São Paulo: Fundação telefônica, 2013.

ROJO, Roxane. Multiletramentos, Multilinguagens e Aprendizagens. Grupo de Pesquisa da Relação Infância, Adolescência e Mídia. Universidade Federal do Ceará: Grim UFC, 15 out. 2013.2 Disponível em: http://www.grim.ufc.br/index.php?option=com_content\&view=article\&id=80:entrevista -com-roxane-rojo-multiletramentos-multilinguagens-eaprendizagens\&catid=8:publicacoes\&Itemid=19/. Acesso em: 22 mai. 2019.

ROJO, Roxane. Pedagogia dos multiletramentos: diversidade cultural e de linguagens na escola. São Paulo: Parábola, 2012. Disponível em: http://catalogo.educacaonaculturadigital.mec.gov.br/hypermedia.../rojo_2012.doc. Acesso em: 01 jul. 2019.

SÃO PAULO - Secretaria de Educação do Estado de São Paulo. Currículo do Estado de São Paulo - Ciências da Natureza e suas Tecnologias - Ensino Fundamental - Ciclo II e Ensino Médio - SEE, 2011.

SEIDLHOFER, Barbara. Understanding English as a Lingua Franca. Oxford: Oxford University Press, 2011.

SILVA, Silvio Profirio da. Texto visual na Educação Infantil: Contribuições para construção do conhecimento da criança. Revista Arredia, Dourados, MS, Editora UFGD, v. 3, n. 5, p. 77-101, ago./dez. 2014. 
SOUZA-LUZ, Ana Claudia Cury Calia de; CRISTOVÃO, Vera Lúcia Lopes. Planejamento pedagógico na avaliação de ferramentas de ensino de línguas estrangeiras. In: ARAÚJO, V. C.; SILVEIRA, P. da (Org.). Da teoria e da Prática: o ensino de línguas estrangeiras em discussão. v. 1. Campinas: Pontes Editora, 2017. p.1-91.

Criar jogo da memória. https://www.youtube.com/watch?v=rvm0q-vNVEI. Acesso em: 15 jul. 2021.

Rimas infantis e populares em inglês. http://www.uspstudios.co/ Acesso em: 10 jul. 2021.

Three Little Pigs. https://www.youtube.com/watch?v=2s7cz6p7jew. Acesso em: 15 jul. 2021.

Recebido em: 21/09/2021

Aceito em: 04/01/2022 